\title{
Wait Times for Carotid Endarterectomy, London Ontario 2006-2007
}

\author{
Erin Dyer, Stephen Lownie, Gary Ferguson (in memoriam)
}

\begin{abstract}
Objective: To examine time delays and identify factors that affect wait times from index neurological event to carotid endarterectomy in patients with symptomatic carotid stenosis treated at a regional neurosurgical referral centre. Methods: We performed a retrospective audit over two years of all patients who underwent a carotid endarterectomy at University Hospital, London, Ontario. The number of days was calculated from first neurological event through until surgery. Results: Eighty-nine carotid endarterectomies (CEAs) were performed by four surgeons during the years 2006 and 2007. From the first neurological event, the median wait time for surgery was 111 days, while from the last event the median wait time was 83 days. There was 19 days' wait between specialist / TIA clinic appointment and the receipt of neurosurgical referral. Median wait time for diagnostic imaging was eight days for carotid Doppler ultrasound and 15 days for CT or MR angiography. There was a 44 day wait from receipt of neurosurgical referral to the date of surgery. Only three patients $(4 \%)$ received CEA within two weeks of their last neurological event. There was a trend towards a difference in wait times between inpatients and outpatients, but no difference between females compared with males, or between patients presenting with stroke versus TIA. Discussion: Median wait times for CEA after first neurological event was over three months at our center, reflecting the diagnostic workup required in TIA as well as the lack of a systematic approach. This is the subject of continued study at our institution.
\end{abstract}

RÉSUMÉ: Temps d'attente pour une Endartérectomie Carotidienne à London, Ontario, en 2006 et 2007. Objectif : Le but de l'étude était d'examiner le temps d'attente et d'identifier les facteurs qui influencent le temps d'attente, du premier événement neurologique jusqu'à l'endartérectomie carotidienne, chez les patients présentant une sténose carotidienne symptomatique qui ont été traités dans un centre de référence neurochirurgical régional. Méthode : Nous avons effectué une vérification des dossiers de tous les patients qui ont subi une endartérectomie carotidienne au cours d'une période de 2 ans à l'University Hospital, à London, Ontario. Nous avons calculé le nombre de jours écoulés depuis le premier événement neurologique jusqu'à la chirurgie. Résultats : Quatre-vingt-neuf endartérectomies carotidiennes (EC) ont été effectuées par 4 chirurgiens au cours de 2006 et de 2007. Le temps médian d'attente pour la chirurgie depuis le premier événement neurologique était de 111 jours et il était de 83 jours depuis le dernier événement neurologique. Le temps d'attente pour obtenir un rendez-vous avec un spécialiste/à la clinique d'itc suivant la réception de la demande de consultation était de 19 jours. Le temps d'attente médian pour l'imagerie diagnostique était de 8 jours pour un écho-doppler de la carotide et de 15 jours pour une angiographie par tomodensitométrie ou par résonance magnétique. De la réception de la demande de consultation en neurochirurgie à la date de la chirurgie, il y avait 44 jours d'attente. Seulement 3 patients (4\%) ont subi une ec dans les deux semaines suivant leur dernier événement neurologique. Il existait une tendance statistique vers une différence dans le temps d'attente entre les patients hospitalisés et les patients externes, mais aucune différence entre les hommes et les femmes ou entre les patients ayant consulté pour un accident vasculaire cérébral par rapport à ceux qui avaient présenté un accès ischémique transitoire cérébral. Discussion : Le temps médian d'attente pour une ec après le premier événement neurologique était de plus de 3 mois dans notre centre, ce qui tient compte de la démarche diagnostique requise lors d'un itc ainsi que de l'absence d'une approche systématique. Des études sur ce sujet sont en cours dans notre institution.

Can J Neurol Sci. 2013; 40: 330-333

Randomized clinical trials have demonstrated that carotid endarterectomy (CEA) is beneficial in the prevention of stroke due to symptomatic severe carotid artery stenosis ${ }^{1-3}$. In the first days after transient ischemic attack (TIA) or minor stroke, the risk of subsequent major stroke is high ${ }^{4-7}$. Thus early initiation of diagnostic workup and treatment, ideally within two weeks, confers the most benefit ${ }^{8-10}$. The number needed to treat (NNT) if treatment is completed within two weeks is three. This NNT progressively increases up to 11 if the time to treatment increases to three months. Despite such evidence, regional and worldwide audits have found significantly higher wait times than two weeks $^{11,12}$. For example, at designated Canadian stroke centres between 2003 and 2006, median wait time to CEA was 30 days, with only one-third of patients receiving surgery within two weeks from last ischemic event ${ }^{11}$. In the UK during 2005-2007 only $20 \%$ of patients received their operation within two weeks ${ }^{12}$. In the Oxfordshire study the median time to surgery from TIA was 18 weeks ${ }^{4}$.

The goal of this study was to determine the wait times from both the first and the last neurological event through to the date

From the Division of CNS, London Health Sciences Center, University of Western Ontario, University Hospital, London, Ontario, Canada.

Received April 2, 2012. Final Revisions Submitted December 11, 2012. Correspondence to: Stephen P. Lownie, Neurosurgery and Neuro-Radiology, University of Western Ontario, London Health Sciences Center, University Hospital, 339 Windermere Road, London, Ontario, N6A 5A5, Canada.

Email: Steve.Lownie@1hsc.on.ca. 
of surgery at a regional Canadian neurosurgical centre in order to identify any variables which might be modified to improve wait times.

\section{METHODS}

This study was conducted under an approved ethics protocol (UWO Research Ethics Board No. 7962E). All patients undergoing CEA at University Hospital, London, Ontario during the two-year period between Jan 1, 2006 and Dec 31, 2007 were included for retrospective review. Data obtained included age and gender, date of first and last neurological event, date of referral to neurosurgeon and date of neurosurgical appointment, date of preadmission clinic, and date of surgery. The mean and median number of days between events and various dates was determined. Student's t test was used to evaluate statistical differences between subgroups. Results were considered significant at two-tailed $p<0.05$.

\section{Results}

Over the two year study period, 89 CEAs were performed in 88 patients. In total, 49 CEAs were performed in 2006 and 40 in 2007. One patient had bilateral endarterectomies. All patients were symptomatic with TIA or minor stroke and with moderate to severe stenosis as determined by two or more concordant imaging studies. Of the 88 patients, 26 (30\%) were female and $62(70 \%)$ were male. Mean age was 67 years (range 45 to 88 years). Clinical presentation included stroke (24\%), hemispheric TIA (23\%), transient monocular blindness (19\%) or both hemispheric and ocular events $(19 \%)$. Both stroke and TIA occurred in $10 \%$, while $3 \%$ presented with retinal infarct. Imaging studies, most commonly carotid Dopplers followed by computed tomographic angiography (CTA) or magnetic resonance angiography (MRA), were used to confirm the severity of stenosis. Stenosis was measured according to NASCET criteria ${ }^{1}$. Severity of stenosis was graded as severe (70-90\%) in $57 \%$, approaching near occlusion in $35 \%$, and moderate in $8 \%$.

Ascertainment of the wait times from first neurological event to CEA was possible in 82 of 89 cases, while from the neurological event it was obtained in 77 of 89 cases. Mean and median wait times from the first neurological event to completion of CEA were 130 days and 111 days, respectively. A median 0 days (mean of 11) elapsed from first neurological event until first medical attention. First medical attention was by the patient's family physician in $10 \%$, the hospital emergency department in $20 \%$, other regional emergency department in $28 \%$, and unknown in $40 \%$. If first visit was to a primary care provider, a median of 19 days (from emergency room visit) or 26 days (from family physician) elapsed during the wait for appointment at a stroke prevention facility or with a specialist (TIA clinic, neurologist, internal medicine). Median wait time for diagnostic imaging was eight days for carotid ultrasound and 15 days for CTA or MRA. There was 19 days' median wait between specialist appointment and receipt of neurosurgical referral. Incorporated within this was a median of 11 days' wait between the completion of imaging and receipt of neurosurgical referral. From receipt of neurosurgical referral, a median wait of 44 days elapsed to the performance of CEA. This included a median 15 days between neurosurgical appointment and preadmission clinic visit, followed by a further median 13 days to date of CEA. Nine patients who required additional imaging spent an additional 40 days waiting.

Three patients $(4 \%)$ received treatment within two weeks of their event. Thirty-nine $(51 \%)$ had surgery between two weeks and within three months; 21 (27\%) between three months and five months; and 13 (17\%) after more than five months.

Wait times in seven patients $(8 \%)$ were longer due to medical co-morbidities, due to the need for additional preoperative testing, or due to patient factors. Medical co-morbidities included diabetic glucose management, angina, and cardiac workup. Additional testing included femoral angiography. Patient factors included one patient who initially declined surgery and another who cancelled, both needing subsequent rebooking.

Median wait time for inpatients from last neurological event was 59 days, whereas median wait time for the 65 outpatients was 89 days, a difference of 40 days which did not quite approach statistical significance $(\mathrm{p}=0.086)$. There was no difference based on clinical presentation (stroke vs. TIA) or based on gender.

\section{Discussion}

Performance of CEA within two weeks of the last ischemic event has been shown to confer the greatest benefit in stroke prevention ${ }^{10}$. Some concern persists though with respect to procedural risk during early surgical intervention after stroke $^{13,14}$. A stroke and death rate of $2.4 \%$ with surgery performed within 14 days has been observed to increase to $4.3 \%$ when surgery is performed within seven days ${ }^{15}$. However even with the increased procedural risk, surgery would still prevent more strokes than when it is delayed more than four weeks.

We therefore sought to determine local wait times at our centre and the potential factors which could contribute to delay (Figure). Our study found wait times in keeping with those of other published reports. The median wait time from neurosurgical assessment to surgery was 28 days. This figure is similar to the published wait time of 41 days for major centres within the province of Ontario (Ontario Ministry of Health and Long Term Care (http://www.waittimes.net)).

Prospective studies in the UK have demonstrated median times from neurological event to surgery of 100 days $^{4}$. In the General anesthesia versus local anesthesia (GALA) trial the median time from symptoms to surgery was 82 days ${ }^{16}$. In the European Carotid Surgery Trial involving multiple countries, only $34 \%$ received surgery within four weeks of symptoms ${ }^{12}$. Median wait time was greater than two months, with no country achieving a median wait time of less than two weeks. Based on these studies and others, there is a need to develop effective strategies to reduce wait times ${ }^{17}$.

It is important to note that the wait time from the date of the decision to treat does not encompass the preceding time between clinical presentation and referral. We identified numerous delay points between last neurological event and neurosurgical referral. Delays from last neurological event to neurosurgical referral were a median of 37 days. Delay was multi-factorial including patient factors (delayed presentation to medical attention, co-morbidities), physician factors (delays in diagnosis, work-up and referral), imaging factors, and surgeon factors ${ }^{11,16}$. 


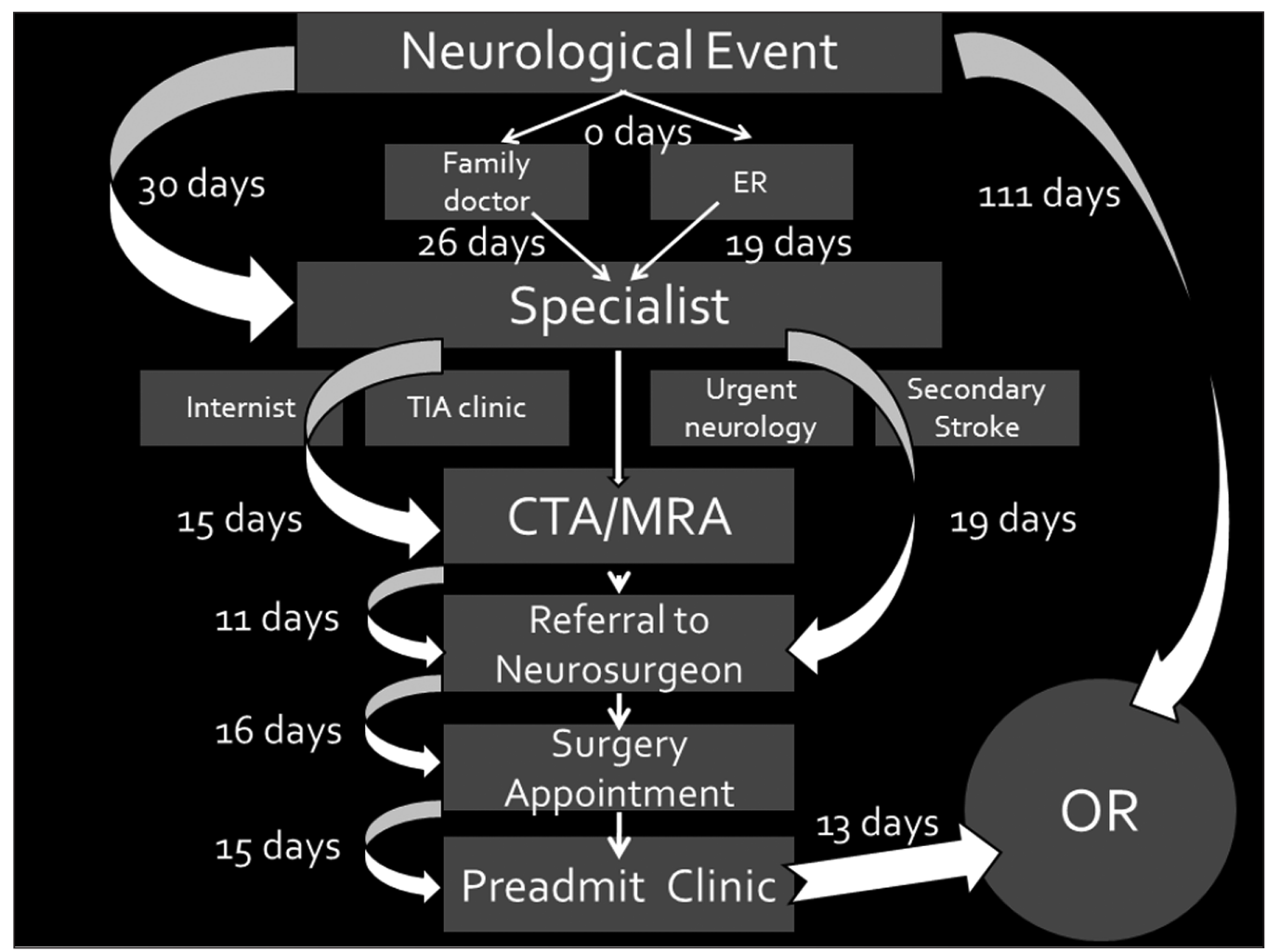

Figure: Wait times in median number of days between major points of care after TIA or minor stroke to carotid endarterectomy.

Imaging performed at our institution typically included carotid Doppler ultrasound and a second imaging modality, often CTA. The pattern of patient access to imaging was highly variable. Two or more weeks often elapsed during imaging workup. Ultrasound was typically performed first, and perhaps could have been used to fast track patients to further imaging and referral.

In this study, the most common approach to triage was outpatient referral to a secondary stroke specialist. Although upwards of 37 days elapsed with this approach, it has been identified as faster than referral via the primary care physician alone $^{12}$. Admission to hospital may have facilitated access to imaging and neurosurgery referral. However our institution, like most, has limited hospital bed access. We found non-significant differences between inpatient and outpatient management within the limitations of our small study.

This study did not address the issue of patients waiting for surgery who may have sustained a major stroke or died, or who developed complete arterial occlusion. Doppler $\mathrm{CO}_{2}$ testing can identify patients at high risk for early stroke due to hemodynamic compromise ${ }^{18}$, although this is not in routine use at most centres. High risk ultrasonographic and magnetic resonance imaging (MRI) features, including plaque ulceration and intra-plaque hemorrhage, could also be useful in triaging ${ }^{1}$.

Efforts to improve wait times should ideally reflect the Canadian Stroke guidelines, which may also include expansion of surgical resources to provide a rotating carotid surgery clinic schedule $^{19}$. A dedicated TIA clinic was in existence during the years encompassed by this study, as well as, weekly dedicated CTA or MRA imaging slots. Other strategic approaches include the institution of dedicated clinical nurse specialist triage, and the development of a "fast-track carotid clinic," approaches which were put into place subsequent to the time period of this study. The results of these strategies are currently under assessment at our institution.

\section{ACKNOWLEDGEMENTS}

Although Dr. Ferguson passed away December 4, 2011 his leadership in the NASCET trial and dedication to stroke prevention through carotid endarterectomy served as an inspiration for generations of London neurosurgical residents. With fond reminiscence, every carotid plaque was simply "the worst" Dr. Ferguson had ever seen. He is greatly missed. We also gratefully acknowledge the neurosurgical staff (Drs. W. Ng and N. Duggal) who generously contributed time and resources to performing CEA. The authors thank L. Thompson, J. Haston, N. Whiteside and M. Rummel for their dedicated administrative assistance. 


\section{REFERENCES}

1. North American Symptomatic Carotid Endarterectomy Trial Collaborators. Beneficial effect of carotid endarterectomy in symptomatic patients with high-grade carotid stenosis. N Engl J Med. 1991;325:445-53.

2. European Carotid Surgery Trial Collaborators. Randomised trial of endarterectomy for recently symptomatic carotid stenosis: final results of the MRC European Carotid Surgery Trial (ECST). Lancet. 1998;351:1379-87.

3. Rothwell PM, Eliazaiw M, Gutnikov SA, et al. Analysis of pooled data from the randomized controlled trials of endarterectomy for symptomatic carotid stenosis. Lancet. 2003;361:107-16.

4. Fairhead JF, Mehta Z, Rothwell PM. Population-based study of delays in carotid imaging and surgery and the risk of recurrent stroke. Neurology. 2005;65:371-5.

5. Coull AJ, Lovett JK Rothwell PM. Early risk of stroke after a TIA or minor stroke in a population based incidence study. BMJ 2004;328:326-8.

6. Marnane M, Ni Chroinin D, Callaly E, et al. Stroke recurrence within the time window recommended for carotid endarterectomy. Neurology. 2011;77:738-43.

7. Giles MF, Rothwell PM. Risk of stroke early after transient ischaemic attack; a systematic review and meta analysis. Lancet Neurol. 2007;6:1063-72.

8. Lovett JK, Coull AJ, Rothwell PM. Early risk of recurrent stroke by etiological subtype: implications for stroke prevention. Neurology. 2004:62:569-74.

9. Luengo-Fernandez R, Gray A, Rothwell PM. Effect of urgent treatment of TIA and minor stroke on disability and hospital costs (EXPRESS study): a prospective population-based sequential comparison. Lancet Neurol. 2009;8(3):235-43.

10. Rothwell PM, Eliasziw M, Gutnikov SA, Warlow CP, Barnett HM. Endarterectomy for symptomatic carotid stenosis in relation to clinical subgroups and timing of surgery. Lancet. 2004;363: 915-24.
11. Gladstone DJ, Oh J, Fang J, Lindsay P, Tu JV, Silver FL, Kapral MK. Urgency of carotid endarterectomy for secondary stroke prevention. Results from the registry of the Canadian Stroke Network. Stroke. 2009;40: 2776-82.

12. Halliday A, Lees T, Kamugasha D, et al. Waiting times for carotid endarterectomy in UK: observational study. BMJ. 2009;338: b1847.

13. Rerkasem K, Rothwell, PM. Systematic review of the operative risks of carotid endarterectomy in recently symptomatic stenosis in relation to timing of surgery. Stroke. 2009;40(10):564-72.

14. Rockman CB, Maldonado TS, Jacobowitz GR, Cayne NS, Gagne PJ, Riles TS. Early carotid endarterectomy in symptomatic patients is associated with poorer perioperative outcomes. J Vasc Surg. 2006;44:480-7.

15. Salem MK, Sayers RD, Bown MJ, Eveson DJ, Robinson TG, Naylor AR. Rapid access carotid endarterectomy can be performed in the hyperacute period without significant increase in procedural risk. Eur J Vasc Endovasc Surg. 2010;41(2):222-8.

16. Dellagrammaticas D, Lewis S, Colam B, Rothwell PM, Warlow CP, Gough M. GALA trial collaborators. Cartoid endarterectomy in the UK; acceptable risks but unacceptable delays. Clin Med. 2007;7:589-92.

17. Prasad J, Husereau D, Nagpal S, et al. Wait times among patients with symptomatic carotid artery stenosis requiring carotid endarterectomy for stroke prevention. J Vasc Surg. 2012;56: 661-7.

18. Blaser T, Hofmann K, Buerger T, et al. Risk of stroke, transient ischemic attack, and vessel occlusion before endarterectomy in patients with symptomatic severe carotid stenosis. Stroke. 2002; 33:1057-62.

19. Lindsay P, Bayley M, Hellings C, et al. Canadian best practice recommendations for stroke care (updated 2008). CMAJ. 2008; 179(suppl):S1-S25. 